\title{
7. Transmedia Character Building
}

\author{
Textual Crossovers in the Star Wars Universe \\ Lincoln Geraghty
}

As the other chapters in this collection attest, Star Wars is a prime example both of contemporary transmedia storytelling and of media franchising. The story and brand spread across multiple media platforms and textual commodities, driven by the ongoing battle between the forces of good and evil. Star Wars is a "commercial supersystem of transmedia intertextuality," or what Henry Jenkins, Marc Steinberg, and Colin B. Harvey, among others, have more recently described as the phenomenon of transmedia storytelling: a strategy informing the creation and development of megafranchises like Star Wars through the dispersal of one storyworld across multiple media platforms. ${ }^{1}$ Transmedia storytelling and accompanying media franchising contribute to how Hollywood builds on its filmic output, ensuring longevity and financial success well beyond the first iteration of a text. For Derek Johnson, whereas "transmedia storytelling suggests cultural artistry and participatory culture, 'franchising' calls equal if not more attention to corporate structure and the economic organization of that productive labor."2 In this chapter, I broaden Johnson's discussion of the relationship between transmedia storytelling and media franchising to analyze recent developments in the Star Wars storyworld.

More specifically, I argue that certain characters throughout the history of the franchise have been used as transmedia signposts, directing audiences to other media texts that surround the original movies. As a result, they have become important signifiers of Star Wars's transmedia history, carriers of inherent narrative meaning and objects of fan-cultural value. For example, Boba Fett began as an animated character in the Holiday Special

\footnotetext{
1 Marsha Kinder, Playing with Power in Movies, Television and Video Games: From Muppet Babies to Teenage Mutant Ninja Turtles (Berkeley: University of California Press, 1991), 3; Henry Jenkins, Convergence Culture: Where Old and New Media Collide (New York: New York University Press, 2006); Colin B. Harvey, Fantastic Transmedia: Narrative Play and Memory Across Science Fiction and Fantasy Storyworlds (Basingstoke: Palgrave MacMillan, 2015); Marc Steinberg, Anime's Media Mix: Franchising Toys and Characters in Japan (Minneapolis: University of Minnesota Press, 2012).

2 Derek Johnson, Media Franchising: Creative License and Collaboration in the Culture Industries (New York: New York University Press, 2013), 33.
} 
(1978), then made his first film appearance in The Empire Strikes Back, and was later added back into the 1997 special edition re-release of $A$ New Hope. Since the 1990s, his backstory has been fleshed out in novels and comics as well as in the prequel films and animated series, The Clone Wars and Rebels. Characters such as Darth Maul, Ahsoka Tano, Grand Admiral Thrawn, and Saw Gerrera either debuted in the films and moved to other platforms or were created as spin-off characters in novels and television to later appear in films and series. The regular remediation of such characters, joining the different media together, suggests that the Star Wars transmedia storyworld is both flexible and reflexive. These characters have been transformed and reimagined to fit the transmedia narrative at different stages of its evolution over the last 40 years while also acting as catalysts for new stories and new franchising opportunities.

Disney's announcement in 2014 that the canon was to be reset in order to make the six original films and The Clone Wars and Rebels television series "immoveable objects" in the narrative universe, from which new stories and texts would originate, underscores their strategy to rebuild Star Wars for a new generation. ${ }^{3}$ In anticipation of the release of The Force Awakens, the resetting of the canon and creation of the Lucasfilm Story Group cleared the slate and deleted previously established characters, such as Luke and Leia's respective Jedi offspring, so as to introduce similar characters such as Rey (assumed by many to be Luke's daughter) and Kylo Ren (Ben Solo). But, where Disney was originally criticized for abandoning the EU and keystone antagonists like Thrawn, it is now reusing old fan favorites to shape the universe for new audiences. As a corporate licensor, Disney is keenly aware that it has to extend the franchise for future storytelling while playfully engaging with its past. New toys, novels, guidebooks, comics, video games, films, and television series all contribute to a complex narrative network of Star Wars texts. Key characters in effect represent those "immoveable objects" when used strategically in marketing campaigns. They become texts in themselves: synecdochal signifiers of the Star Wars transmedia universe. For Jenkins, "the core aesthetic impulses behind good transmedia works are world-building and seriality." Iconic characters in the Star Wars universe are integral to this process since they help to establish the fictional

3 “The Legendary Star Wars Expanded Universe Turns A New Page," StarWars.com, April 25, 2014, accessed May 8, 2017, http://www.starwars.com/news/the-legendary-star-wars -expanded-universe-turns-a-new-page.

4 Henry Jenkins, "The Aesthetics of Transmedia: In Response to David Bordwell (Part Two)," Confessions of an Aca-Fan: The Official Weblog of Henry Jenkins, September 13, 2009, accessed May 8, 2017, http://henryjenkins.org/2009/og/the_aesthetics_of_transmedia_i_1.html. 
world and aid in the serialization of the fictional narrative. William Proctor and Matthew Freeman describe this relationship between marketing, merchandise, and the text as the "transmedia economy" of Star Wars. ${ }^{5}$ This chapter therefore highlights the interconnected nature of corporate production, fan consumption, and transmedia world-building in the context of cross-platform character development.

Marc Steinberg's discussion of what he terms anime's "media mix" provides a helpful framework for understanding what has happened with new and established characters throughout the transmedia history of Star Wars. Media mix, as a "term for the cross-media serialization and circulation of entertainment franchises," shares much with Henry Jenkins's examination of contemporary convergence culture. ${ }^{6}$ However, Steinberg traces a longer history of the term, suggesting that it starts with the emergence of anime on Japanese television in the 196os. More than a style, anime is a mode of cultural production and consumption in which animated characters and franchises mix and merge across media platforms. Audience consumption of these franchises and animated characters is not only about possession (purchasing and collecting merchandise and images) but also about participation. Thus, according to Steinberg,

the anime media mix simultaneously creates (1) the character merchandise as material object, (2) the world to which the character merchandise belongs, and (3) the character as immaterial connective agent guaranteeing the consistency of this ever-expanding world.?

Before the Disney era, we see evidence of this media mix in how Lucas and Lucasfilm continually manipulated the Star Wars narrative, promoted it through proliferation of merchandising, and expanded the potential for transmedia storytelling through the continual retelling and reordering of individual characters and their histories. In the following analysis of transmedia crossovers, I look at three specific characters in detail: Boba Fett, Darth Maul, and Grand Admiral Thrawn. These characters represent different iterations and time periods in the Star Wars franchise: Fett is from the original trilogy and has existed in various literary versions since the

5 William Proctor and Matthew Freeman, “'The First Step into a Smaller World': The Transmedia Economy of Star Wars," in Revisiting Imaginary Worlds: A Subcreation Studies Anthology, ed. Mark J.P. Wolf (New York: Routledge, 2016), 223.

6 Steinberg, Anime's Media Mix, viii.

7 Steinberg, Anime's Media Mix, 200. 
beginning; Maul is from the prequel trilogy and has undergone some very recent changes in appearance and characterization in animated spin-offs; and Thrawn, originally created in the EU following the original trilogy, has now been reincorporated into the canon post-Disney. Moreover, all three characters are notionally villains and thus serve as regular dramatic foils in various media versions of the Star Wars metatext: Fett as bounty hunter routinely pursues main protagonists such as Luke and Han Solo; Maul carries a vendetta against Obi-Wan Kenobi; and Thrawn serves as overarching nemesis of the whole Rebel Alliance. These crossover characters have also been especially popular amongst fans, pointing to their longevity and importance to the overall Star Wars universe.

\section{Boba Fett: Perennial Antagonist}

Boba Fett epitomizes Lucasfilm's original attempts to rewrite backstory through transmedial migration, as Lucas manipulated his core characters to establish and to expand the Star Wars universe. With his story as peripheral bounty hunter turned genetic progeny of the clone army, Fett highlights Lucas's original strategy for expanding the narratives of incidental characters. While The Empire Strikes Back was his first canonical appearance, his animated form seen in the Holiday Special preceded this and became part of the paratextual infrastructure surrounding the marketing and merchandising of A New Hope following its 1977 release. His animated form acted as an unofficial introduction to the character, depicting him as a bounty hunter employed by Darth Vader to find Luke, Leia, and Han, and thereby foreshadowing his eventual role in The Empire Strikes Back and Return of the Jedi. With the remastered re-release of the original trilogy in 1997 in anticipation of The Phantom Menace, Fett was inserted into A New Hope. His presence in Mos Eisley, during the scene in which Jabba the Hutt confronts Han Solo, retroactively asserts his presence throughout the original trilogy. Lucas likely included Fett in this deleted scene from A New Hope because he had very quickly become a cult favorite for action figure collectors. ${ }^{8}$ However, Fett also had several EU stories, novels, and comics devoted to fleshing out his backstory so that Fett's insertion into

8 Such action figures "underscore the plural in [Star Wars], declaring the central frame and theme to be that of a never-ending series of grand and cosmic battles of mythic proportions." Jonathan Gray, Show Sold Separately: Promos, Spoilers, and Other Media Paratexts (New York: New York University Press, 2010), 180. 
A New Hope works to substantiate and build upon the growing mythos surrounding the secretive and unmasked antihero, while at the same time asserting Lucas's authorship.

Lucas as author is again emphasized in the prequels, particularly in Attack of the Clones, wherein audiences learn about Fett's origin: he is a clone of the bounty hunter Jango Fett, who dons the same Mandalorian armor and raises the clone as his son. The story of Jango's clone-son was later developed and expanded throughout five seasons of The Clone Wars; Boba Fett's relationships with other well-known bounty hunters, such as Bossk, became central storylines and bred familiarity for those wanting to know more about his eventual journey to becoming Han Solo's nemesis. Before Attack of the Clones and The Clone Wars, Fett's off-screen life is explored in a series of short stories published as part of the Tales series edited by Kevin J. Anderson. In "A Barve Like That: The Tale of Boba Fett" by J.D. Montgomery, published in Tales from Jabba's Palace, readers learn that Fett survives his plunge into the Sarlacc Pit in Return of the Jedi. ${ }^{9}$ Montgomery, writing as Daniel Keys Moran, follows this up in "The Last One Standing: The Tale of Boba Fett" published in Tales of the Bounty Hunters; Montgomery presents Fett as a one-time lawman, a sympathetic version of the determined and haunted loner. ${ }^{10}$ Working to add depth to the character, while not necessarily making sense in terms of the narrative timeline, these textual examples of Fett's transmedia narrative are indicative of what Andrew J. Friedenthal calls the phenomenon of "retroactive continuity," more commonly abbreviated as "retconning." ${ }^{11}$ He argues that, while cinematic blockbuster franchises now "utilize the complexity of their fictional universes in order to refresh the narratives and maintain audience interest across multiple platforms," this strategy has its roots in the comic-book industry. ${ }^{12}$ As Fett's ever-growing transmedia story spans a number of texts across different media platforms - comics, novels, games, television and films - individual authors adapt the character to fit plot, medium, and merchandising opportunities.

Giving Fett an origin story in Attack of the Clones, however, in no way devalues what came before-neither in the original films nor in the EU.

9 J.D. Montgomery, "A Barve Like That: The Tale of Boba Fett," in Tales from Jabba's Palace, ed. Kevin J. Anderson (New York: Bantam Books, 1996).

10 Daniel Keys Moran (J.D. Montgomery), "The Last One Standing: The Tale of Boba Fett," in Tales of the Bounty Hunters, ed. Kevin J. Anderson (New York: Bantam Books, 1996).

11 Andrew J. Friedenthal, Retcon Game: Retroactive Continuity and the Hyperlinking of America (Jackson, MS: University Press of Mississippi, 2017), 7 .

12 Friedenthal, Retcon Game, 10. 
New insights into the character do not start his story over again, as with a reboot, but rather add depth to what fans already perceive as a complicated and important backstory. The subtle changes to Fett-for example, his voice being redubbed in the original trilogy for the 2004 DVD re-release so it matches Jango Fett's from the prequels - are for continuity and are not meant to redraw the character, although many fans felt this was further evidence of Lucas tinkering too much. This example serves to unite the various iterations of Fett depicted over the 40-year history of the franchise, while familiarizing the character to contemporary audiences.

In his analysis of comic-book reboots, William Proctor argues that "the retcon differs from the reboot in the sense that it alters elements of a series' chronology without collapsing the narrative continuum altogether." ${ }^{13}$ What has happened over time with Boba Fett is a continuous and purposeful attempt to draw and redraw the character to fit with new story developments. Because he proved to be so popular in paratexts, his constant presence needs to be tied into the overall filmic story arc while at the same time remaining as true to the character's established personality traits as possible. The retconning of Fett has therefore meant that he is able to move from new text to old text and back again with little disruption to the canon.

\section{Darth Maul: From Prequel to Sequel}

Unlike Boba Fett, who became an instant fan favorite in spite of his brief appearances, the relatively little screen time given to Darth Maul in The Phantom Menace endeared him neither to critics nor to fans. Indeed, Todd McCarthy for Variety said in his review of the film, "As the most widely anticipated and heavily hyped film of modern times [...] [it] can scarcely help being a letdown on some levels, but it's too bad that it disappoints on so many." Maul gets only a brief mention, because he "doesn't say much but proves to be a particularly dexterous opponent of the jedis [sic]." ${ }^{14}$ Even now, some fan websites reflect upon his rather lackluster dialogue and ignominious death in the furst prequel, citing the lack of original character development as one of the main reasons for their intense dislike.

13 William Proctor, “Ctl-Alt-Del: Retcon, Relaunch, or Reboot?” Sequart, February 8, 2013, accessed May 8, 2017, http://sequart.org/magazine/18508/clt-alt-del-retcon-relacung-or-reboot/. 14 Todd McCarthy, “Review: 'Star Wars: Episode I-The Phantom Menace," Variety, May 10, 1999, accessed May 15, 2017, http://variety.com/1999/film/reviews/star-wars-episode-i -the-phantom-menace-1117499730/. 
But Maul's death at the end of The Phantom Menace was not the last fans saw of the character. Indeed, in the years since The Phantom Menace, Maul has become a cross-series regular. I want to consider in this section how his character has survived criticism to emerge as a pivotal character for new storytelling. As with many villains, his backstory was first fleshed out in the EU, which gave insight into his training by Darth Sidious and filled in some of the gaps between his apprenticeship and his final mission to kill QuiGon and Obi-Wan. Many of his stories appeared in the Dark Horse comics, particularly in an anthology of short stories called Star Wars: Visionaries (2005). This follows in the tradition of the Tales series of books published in the 1990s: a compilation of shorter vignettes focusing on background characters that expand the storyworld. The fact that his legs and torso were separated in the film did not stop author Aaron McBride from writing about Maul's search for revenge in the comics story "Old Wounds," which depicted him with robotic legs and larger cranial horns seeking revenge against the Jedi after Revenge of the Sith, only to die at the hands of Owen Lars on Tatooine. ${ }^{15}$

"Old Wounds" proved prophetic, since the writers of The Clone Wars later bring him back from the dead, give him new cybernetic implants and legs, and set him on a journey first to serve his old master again but then to seek out both Sidious and Obi-Wan in the animated series. Over seasons four and five of The Clone Wars and season two of Rebels, Maul's character becomes as much a victim of the Emperor's plans as the Jedi. A confrontation in The Clone Wars between master and former apprentice almost ends Maul's life for a second time and pushes him to seek revenge on all those who have done him wrong. In season three of Rebels, he is given the chance to confront and kill Obi-Wan on Tatooine, who is himself in hiding and keeping watch over an infant Luke, but Maul ultimately succumbs to the superior swordsmanship of the older Jedi.

This new death scene adds much more weight to his character following his first defeat in the prequel, this time passing away in the arms of his nemesis and wishing for the Chosen One (a reference to Luke) to avenge them both. Over the course of both animated series, Maul becomes a more clearly drawn character, rather than just a henchman for the Dark Side, and his narrative is rewritten to allow greater agency and physical freedom. The relationship between canonical and non-canonical versions of the character also adds importance, as his story becomes much more

15 Aaron McBride, "Old Wounds," in Star Wars: Visionaries, ed. Jeremy Barlow (Milwaukie, OR: Dark Horse Comics, 2005). 
complex in the spin-off novels and comics. Moreover, while non-canonical stories such as "Old Wounds" do not fit within the official narrative now endorsed by Disney, they continue to have an impact, since they are referred to as inspiration for the creation of content in the animated series: on StarWars.com, for example, concept work by McBride for his "Old Wounds" version of Maul is placed beside the final design used in The Clone Wars episode "Revenge." 16

This joining together of two or more iterations of the transmedia franchise works to legitimize the narrative universe in which the story is set. Darth Maul's appearances on both animated series indicate that they are as much a part of the fictional history as the original films, but also represent the larger fantasy to which one must refer for new textual knowledge about the character. Moreover, Maul's reintroduction to the Star Wars canon works to rehabilitate the character following his disappointing reception in 1999. This storytelling trait is not unique to Star Wars and can again be found in comic book superhero narratives, where the integrity of the characters depends upon the existence of a universe in which all the characters owned by a particular company inhabit the same fictional world. ${ }^{17}$ In Star Wars's case, the larger stories that see the Republic on the brink of destruction are made more urgent for the audience because once peripheral and underappreciated characters become important and interesting in their own right; their threat is not restricted to just one series or even one plotline and Maul's importance as a recurring character is re-emphasized through cycles of marketing and merchandising opportunities.

\section{Grand Admiral Thrawn: Heir to the Spin-off}

Darth Maul is an example of how a character shifted from film to books and comics and eventually to television. Even when stories like "Old Wounds" were declared part of the Legends imprint and therefore non-canonical by Disney's Story Group standards, his character had already been given new official life in stories written for the first animated series. Thanks to these appearances and a renewed cybernetic body, fans have reclaimed the character as one of the more popular; charting him at number sixteen on the

16 “Revenge Trivia Gallery," StarWars.com, accessed May 8, 2017, www.starwars.com/tv-shows/ clone-wars/revenge-trivia-gallery.

17 Richard Reynolds, Super Heroes: A Modern Mythology (London: B.T. Batsford, 1992), 37-38. 
all-time greatest Star Wars characters list published by $I G N$ in $2010 .{ }^{18}$ On that same list, EU character Grand Admiral Thrawn appears at number ten. This is evidence of the continuing significance of the EU for fans-characters one to nine on the list were all from the original trilogy —and is illustrative of the importance of "peripheral" characters and stories to the metatextual Star Wars universe. Thrawn first appeared as the new villain, replacing the Emperor, in the Thrawn trilogy of novels (1991-1993) written by Timothy Zahn, set five years after the events of Return of the Jedi. An additional two novels by Zahn, Specter of the Past (1997) and Vision of the Future (1998), give readers more insight into his origins and relationship with the Emperor. As with Maul, his physical appearance (blue skin, red eyes) and characterization as being more imposing than Darth Vader made him a popular choice for adaptations and even a range of action figures.

Thrawn first appeared as a liminal character, very much at the periphery of canonical texts, made physical only through merchandise before the release of The Phantom Menace, and then relegated to Legends status after Disney reset the narrative. But he reemerged as central to the developments depicted in Rebels season three (2016-2017), in charge of eradicating the Rebel threat to the Empire between Revenge of the Sith and A New Hope. Dave Filoni, executive producer of the series, revealed Thrawn's introduction to season three at the London Star Wars Celebration in 2016 - receiving a huge reaction from fans. This was quickly followed up by the announcement that Zahn, original creator of the character, would pen an official novel entitled Thrawn, which would rewrite Thrawn's origin story to fit with the new version on Rebels - thereby retconning Thrawn, like Boba Fett and Maul, to fit the new Disney era. However, whilst canon again seems to take precedence over legend, Filoni's decision to integrate Thrawn into Rebels replicates why the character was created by Zahn for the EU in the first place; namely, as a new dramatic foil for the Rebel Alliance. As Filoni put it, "There's no one to defend [the Rebels] against Thrawn. We want to treat him like a big time villain as much as Darth Vader, but on the strategic, military side of things." Bringing him back into the spotlight was clearly a long-term plan: "Thrawn was always on the list."19 Thus, the Legends still have an impact on Disney's version of Star Wars, as the metatext starts to

18 "Darth Maul \#16," IGN, accessed May 8, 2017, https://web.archive.org/web/20120529123632/ http://www.ign.com:8o/star-wars-characters/16.html.

19 Qtd. in Daniel Krupa and Eric Goldman, "Star Wars Celebration 2016: Rebels Will Treat Thrawn as a Vader-Level Threat," IGN, July 17, 2016, accessed May 8, 2017, http://www.ign.com/ articles/2016/07/17/star-wars-celebration-2016-rebels-will-treat-thrawn-as-a-vader-level-threat. 
accommodate all versions of a character previously spread across different generations and different media platforms.

Star Wars as a long-standing franchise and Thrawn as one of the numerous characters born from within are clearly subject to such flow across media, and through Disney's own network of conglomerated outlets (television channels, movie studios, theme parks, etc.), their audience is potentially infinite. As Henry Jenkins asserts, convergence allows for the archival of and search for new forms of entertainment in which "the flow of content across multiple media platforms" links the web with older media forms such as film and television. ${ }^{20}$ Yet Disney cannot do this alone. To spread its newly acquired IP as far and wide as possible —in different forms and formats—it has undertaken a series of partnerships to benefit from the creative talent and energy offered by production companies, toy manufacturers, and publishers. For Jennifer Holt, post-197os industrial "integration" resulted in synergy that drove media production and, thus, we can see how the integrated strategies of Disney working with creators like Filoni on new Star Wars projects such as Rebels diversify potential markets. ${ }^{21}$ Contemporary media conglomerates seek to maintain their brands through strategies epitomized by the media franchise, transforming all culture into valuable IP.

In the case of Star Wars and the reappearance of Thrawn, this means Disney is protecting its assets by bringing Thrawn under copyright control via Rebels and manages him so as not to dilute the Star Wars brand or risk alienating the target audience. The realignment of the Star Wars canon after 2014 signals Disney's intention to assert their rights as franchise owner and protect the brand from alternative versions - such as the EU — as depicted in the novels, comics, video games, animated series, and roleplaying games since 1977. Thrawn's journey from EU to Rebels shows us how Disney can profit from new character developments while also tying in older stories. Franchises exploit these strategies in service of consolidation and conglomeration by bringing the property under tighter control to prevent the brand from fading or its message from becoming confused. This affords the promise of synergy, where the same content can dominate across markets and generate more income.

20 Jenkins, Convergence Culture, 2.

21 Jennifer Holt, Empires of Entertainment: Media Industries and the Politics of Deregulation, 1980-1996 (New Brunswick, NJ: Rutgers University Press, 2011), 3. 
Synergy, as Kristin Thompson describes it, is about "selling the same narrative over and over in different media." ${ }^{\prime 2}$ For Disney, this means continuing to produce new films and supporting television series, but also promoting Star Wars on its many television channels, in its theme parks, and through its chain of street-level stores. However, according to Derek Johnson, such product diversification reduces the franchise to a selling machine, where business structures are purely about the marketing of the same product regardless of form and content. Star Wars is often described as mythic and therefore timeless and unchanging, but the story in its various incarnations and media-specific formats requires careful consideration and development, as partnerships are constantly negotiated between copyright owner and the creative industries. This is particularly important since many parts of the transmedia franchise are marketed at specific audiences. ${ }^{23}$ Therefore, as a transmedia narrative, Star Wars requires Disney to look outside of its own corporate structures to enlist creative talent like Filoni, who started out with Lucasfilm on The Clone Wars, and Zahn, who has been central to the historical success of the EU storyworld, to drive and extend the property beyond Disney's established network reach.

\section{Conclusion: Creating a Transmedia History}

Many other Star Wars characters move across texts and media in similar ways to the three analyzed above. Indeed, the stories I highlighted by no means exhaust Star Wars's transmedia storyworld. Ahsoka Tano and Saw Gerrera, for example, who both originated in The Clone Wars series, have become integral characters in the expanding fight against the Empire and are increasingly popular with fans. Tano was introduced as Anakin Skywalker's padawan in the 2008 Clone Wars film, designed to help illustrate his own development from brash apprentice to wise master. Over the course of the subsequent series, her character evolved too, becoming an integral part of the Star Wars mythos. Her return from exile in season one of Rebels represented not only a shift across animated series, but also the fulfillment of fan desire to see her face her fallen Jedi Master in his guise as Darth Vader. Rumored plans to cast a live-action movie exploring Tano's life

22 Kristin Thompson, Storytelling in Film and Television (Cambridge, MA: Harvard University Press, 2003), 82.

23 For example, Rebels is aimed at the tween demographic of Disney's XD cable channel. 
underline Filoni's own view that she can exist "in all forms of media." ${ }^{24}$ Saw Gerrera made the jump from animation to live action in Rogue One, where he was played by Forest Whitaker, after having first appeared in the fifth season of The Clone Wars. In Rogue One, he is a much older man, leader of a group of extremist freedom fighters, but his Clone Wars narrative helps to construct audience understandings of his character as new facts are revealed. The film's depiction of Gerrera provides further context for his eventual appearance in season three of Rebels, now more in the mold of Whitaker's filmic portrayal. Tano and Gerrera are therefore by no means limited by their animated origins, further reinforcing the notion that Star Wars's narrative history spreads across various and all forms of transmedia platforms. Furthermore, both The Clone Wars and Rebels have become important texts in themselves, creating new characters and stories that inform our understanding of Star Wars history.

What the characters discussed in this chapter demonstrate particularly well is Star Wars's "media mix" - texts and paratexts, animation and films, history and narrative merging together across multiple continuities. While Boba Fett was clearly the first character to inspire elaborate transmedia crossovers in Star Wars, he has certainly not been the last; Darth Maul and Grand Admiral Thrawn have been incrementally built and rebuilt using earlier and alternate manifestations of their characters. But the old does not simply pave the way for the new: watching and rewatching, reading and rereading newer textual iterations informs and opens up our understanding and enjoyment of older tales. These characters have been transformed and reimagined to serve the transmedia storyworld as the multimedia franchise has grown and expanded. Crossover characters act as catalysts for new stories and new marketing opportunities, while also functioning as familiar narrative signposts directing fans to important moments and events within the transmedia universe of Star Wars.

24 Qtd. in “Ahsoka's Untold Tales Panel | Star Wars Celebration Europe 2016," YouTube video, 1:02:22, posted by “Star Wars," July 15, 2016, accessed May 15, 2017, https://www.youtube.com/ watch? $=\mathrm{IS}_{4} \operatorname{scll}_{5} \mathrm{~J} 4$. 